\title{
"Better to Be Hot than Caught": Excavating the Conflicting Roles of Migrant Material Culture
}

Jason De León

\begin{abstract}
Since the mid-1990s, heightened U.S. border security in unauthorized crossing areas near urban ports of entry has shifted undocumented migration toward remote regions such as the Sonoran Desert of Arizona, where security is more penetrable but crossing conditions are more difficult. Subsequently, a complex smuggling industry has developed in Northern Mexico that profits from helping migrants cross the desert on foot to enter the United States undetected. Desert crossing is now a well-established social process whereby items such as dark clothes and water bottles have been adopted as tools used for subterfuge and survival by migrants. This article highlights ethnographic data on the experiences of migrants and archaeological data collected along the migrant trails that cross the Arizona desert to illustrate the routinized techniques and tools associated with the violent process of border crossing, as well as the dialectical and often oppressive relationship that exists between migrants and objects. [material culture, undocumented migration, border crossing, U.S.-Mexico, archaeology of the contemporary]
\end{abstract}

RESUMEN Desde los 1990s, el augmento de seguridad fronteriza de EE.UU. en áreas cerca de puertos oficiales de entrada ha desplazado la migración indocumentada a regiones remotas como el desierto de Sonora en Arizona donde la seguridad es más penetrable, pero las condiciones para cruzas son más dificiles. Posteriormente, una industria para ayudar los migrantes a cruzar la frontera illegalmente ha desarrollado en el Norte de México. Hoy cruzando el desierto es un proceso social bien establecido. Los migrantes utilizan herramientas como ropa negra y bottelas de agua para eluden la Patrulla Fronteriza y sobrevivir el desierto. Este artículo presenta datos etnográficos de las experiencias de migrantes y datos arqueológicos hubo collectado en los caminos de migrantes en el desierto. Ha demonstrado que las técnicas y instrumentos associado con el proceso violento de cruce son normalizados, tambien la relación entre los migrantes y sus objetos son dialéctica y a veces opresivo.

$I^{\prime}$ m watching Victor and Miguel pack. ${ }^{1}$ We have just returned from a shopping trip where they bought four gallons of water, three cans of beans, 11 cans of tuna, two cans of sardines, half a kilo of limes, two bags of tortillas, a loaf of bread, a bulb of garlic (to rub on their clothes as a defense against snakes), and a can of chiles. They are both trying to cram two gallons of water into their backpacks that are already overloaded with food and clothes. Miguel tells me he has an extra pair of socks in case his feet get wet or he starts to get blisters from his uncomfortable knock-off Adidas sneakers. He has also packed a couple of black T-shirts that he says will help him avoid la migra [Border Patrol]. "It makes it harder for them to see us at night," he says. I ask about the discomfort from the extra heat generated by wearing black in the scorching desert, and he says, "It's better to be hot than caught." Victor then jokes that he should make some room in his small pack to take a couple of caguamas [one-quart bottles of beer]. We laugh at the ridiculous idea but deep down no one is laughing about the fact that the two gallons of water they are each carrying are not even close to what they will need to survive a multiday hike across the desert where recent temperatures have been in the low 100s. They will have to find water along the way and will likely end up drinking the green liquid from the bacteria-laden cattle tanks that dot the southern Arizona desert. These men, who I met several weeks prior while working in a migrant shelter in Nogales, have struggled for almost two weeks to come up with the 30 dollars needed to buy enough food to last 
them both on a multiday crossing. They have attempted this trip several times before and will undertake this one without a paid guide. There is no point in asking them questions like why they don't wear hiking boots or take a compass with them. Hiking boots are an unfamiliar and unattainable commodity to these working-class men. A compass is too expensive and something that Border Patrol would use to classify them as smugglers. If they get caught and labeled as smugglers, they face harsher punishment in the form of long-term jail time. I don't ask them if the few meager goods they are carrying are going to be sufficient to get across the border. I just sit and imagine the unforeseen perils that no one wants to talk about. Later, we hop on a bus and silently ride to the outskirts of Nogales where they will enter the desert on foot. Out of nowhere Victor turns to me and says "A lot of things are going through my head right now. I'm thinking about my family and I'm scared that I am going to die out there. Each time is different; you never know what is going to happen.... The bajadores [armed border bandits] should be out partying tonight because it's Saturday. We should be able to avoid them. We have food and water and God willing we will get across." The three of us get off the bus and walk toward a tunnel that leads out of town. We hug and say goodbye, and Victor walks away jokingly saying he brought the beer after all. I watch them disappear into the darkness of the tunnel and I wonder to myself how anyone can possibly try to prepare for something like this.

\section{INTRODUCTION}

This article is about the materiality and technologies of undocumented border crossing between Sonora, Mexico, and Southern Arizona. It is an analysis of seemingly ordinary items such as clothes, shoes, and water bottles that over the last 20 years have been shaped by the institutionalized border enforcement practices of the U.S. government, the human smuggling industry in Mexico, and by undocumented migrants into a unique set of tools used for subterfuge and survival. For people like Victor and Miguel, and the thousands of other women, men, and children who attempt crossings each year, these common items take on new functions and meaning once brought into the desert and deposited along the many trails that lead from Mexico into Arizona. These items are the tools of the undocumented, and they are relied on to avoid detection by Border Patrol and to survive the Sonoran Desert that has claimed the lives of thousands of people since the mid-1990s (Rubio-Goldsmith et al. 2006). Those who characterize the artifacts left behind by migrants as mere "trash" (see discussion in Sundberg [2008]) fail to recognize the historical, political, and global economic forces that have shaped border crossing into a well-structured social process (Singer and Massey 1998) with a distinct archaeological fingerprint.

Migrants like Victor choose to wear dark clothing because they have been told (and believe) it will help camouflage them in the desert. Although many migrants know that dark clothing raises the body's core temperature and signals to law enforcement that one is a border crosser, this technique continues to be used by thousands of people each year. In this article I demonstrate that while migrant technology and material culture have become somewhat standardized over the last 20 years, it does not necessarily mean that these tools and techniques are effective or even safe. I focus my analysis on three artifact classes (water bottles, shoes, and clothes) to illustrate that a dialectical relationship between border crossers and these objects exists whereby material culture is adopted and employed to achieve a social goal (i.e., successful crossing) and that material culture simultaneously acts on people's bodies, shapes their behavior, and becomes a medium that produces and projects social distinctions (Tilley 2006:61). Material culture is not just a reflection of the social process of border crossing, it actively constitutes and continuously shapes it. I illustrate that the use of these items is determined by a complex and culturally shaped set of processes influenced by many factors including economic constraints, folk logic, enforcement practices, migrant perceptions of Border Patrol, and the human smuggling industry. Moreover, the techniques used during crossings, both individually and collectively, can often have unintended negative consequences. By focusing on the complex and conflicting roles of the deceptively simple objects used by border crossers, I demonstrate how routinized the violent social process of border crossing and its associated tool kit has become, how people mediate their experiences in the desert through everyday objects, and how objects and technologies can create oppressive consequences through both somatic trauma and by marking people as vulnerable migrants.

I draw on ethnographic and archaeological data from the Undocumented Migration Project (UMP), a long-term study of border crossing along the U.S.-Mexico border (see Figure 1) that I have directed since 2008. This project was conceived in an effort to better understand various elements of border crossing, deportation, and the human smuggling industry in Latin America, as well as demonstrate the effectiveness of using an archaeological approach to understand an ongoing and clandestine social process. Archaeological surveys of migrant trails and ad hoc resting areas known as migrant stations were conducted in the Arizona deserts northwest of Nogales during the summers of 2009 and 2010. These surveys occurred in the Border Patrol jurisdiction known as the Tucson Sector, extending from the New Mexico state line to the Yuma, Arizona county line. Migrant stations are places where people rest, eat, change clothes, and leave items behind while crossing into the United States (see Figure 2). To date, the UMP has mapped dozens of migrant stations and collected thousands of artifacts, including water bottles, clothing, and other materials. The ethnographic data were collected in the Mexican towns of Nogales and Altar (see Figure 1) in the summers of 2009 and 2010. Semistructured and informal interviews were conducted in Spanish with hundreds of migrants either before crossing or immediately 


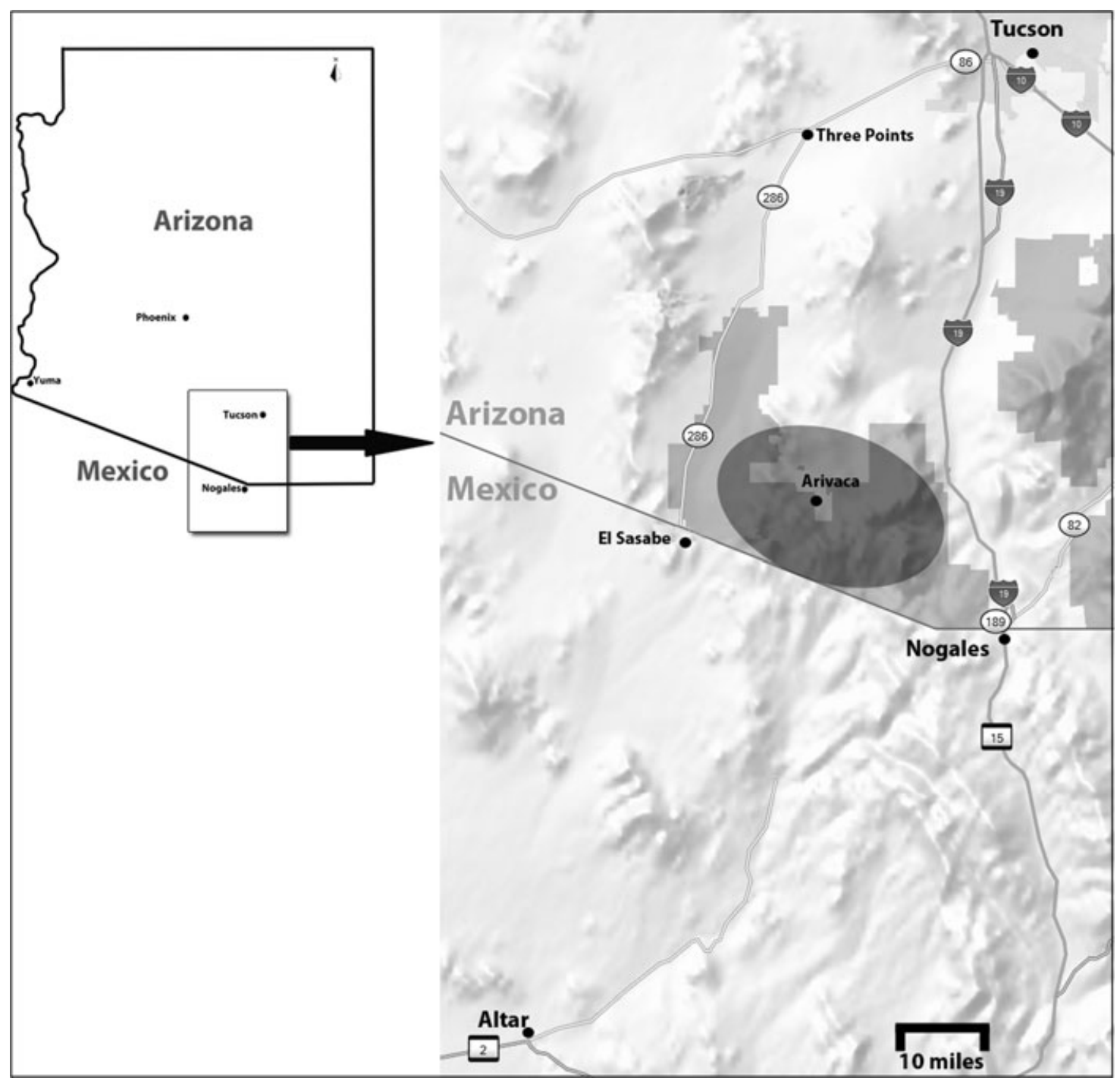

FIGURE 1. Map of study area with major towns and cities mentioned in text. The light gray rectangular areas designate national forest and federal nature reserve lands. The dark shaded circle around the town of Arivaca represents the approximate boundaries of the archaeological survey area.

following deportation. In addition, hundreds of hours of observational data on the day-to-day experiences of deported people in Nogales were collected. Several migrants were also given disposable cameras and asked to photograph their crossing for anonymous publication (see Adler et al. [2007] for similar project), some of which are included here. Although migrants attempt to cross the Sonoran Desert at all times of the year, I focus on the summer months because this is the period when people face the highest risk of death from exposure. Although undocumented migration has slowed over the last several years (see Table 1), summer fatalities have risen suggesting that desert crossings are more dangerous and violent than ever before (McCombs 2011a). The interviews that I collected with migrants during this time of year provide important insight into how people experience the summer desert and the role that material culture plays in surviving this process. ${ }^{2}$

\section{"Prevention through Deterrence"}

Since the mid-1990s, heightened U.S. border security in unauthorized crossing areas near urban ports of entry has shifted undocumented migration toward remote regions such as the Sonoran Desert of Arizona, where security is more penetrable but crossing conditions (e.g., geography and environment) are more difficult. This federal enforcement strategy is known as Prevention through Deterrence (PTD) (Government Accountability Office [GAO] 1997:64-65). PTD along with ever-evolving technologies of enforcement control have increasingly turned the U.S.-Mexico border into a militarized zone where Border Patrol practice a strategy modeled on the Pentagon's Low-Intensity Conflict Doctrine, a policy first designed to suppress domestic insurgencies in the "Third-World" (Dunn 1996). The rampant unofficial racial profiling of Latinos, the impenetrable fencing surrounding ports of entry, the surveillance technologies 


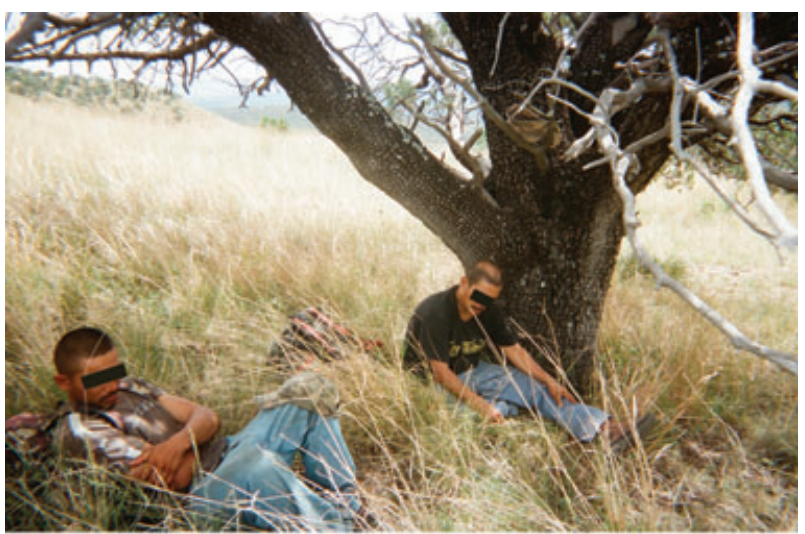

A

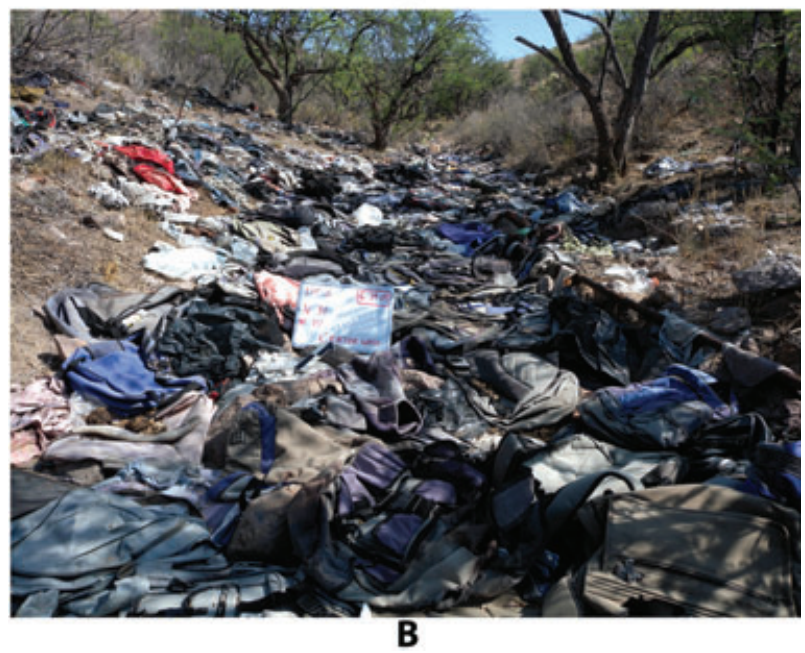

FIGURE 2. A) Resting at a migrant station. B) Over the course of repeated use, migrant stations can develop into sizeable archaeological sites

(e.g., motion sensors), and the desert itself all contribute to a hostile and oppressive environment for migrants.

Initially it was thought that the desert would act as a natural deterrent to migration (Cornelius 2001), but over a decade of research has shown PTD to be ineffective (e.g., Cornelius and Salehayan 2007). This is especially true in Arizona, where despite hundreds of migration-related deaths annually, hundreds of thousands still attempt to cross the vast desert on foot each year to enter the United States without authorization. Rather than deterring, the strategies and policies associated with PTD have helped shape border crossing into a well-organized, dangerous, and violent social process. In Arizona, the busiest crossing point along the southern border, migrants must negotiate a rugged and inhospitable landscape characterized by extreme environmental conditions (e.g., summer temperatures exceeding $115^{\circ} \mathrm{F}$ ) and few water sources. In the summer, injuries and death are common, and many fail to successfully cross after running out of water, becoming dehydrated, or sustaining an injury. Adding to these environmental factors, migrants must also contend with bajadores who assault them and coyotes [human smugglers] who may abandon them in the desert. If migrants are able to overcome these obstacles, they must still evade
Border Patrol who employ sophisticated ground and aerial surveillance technology to detect and capture people.

It is important to note that the data presented here were collected during a moment when major shifts in undocumented migration began to occur. This included a decrease in migration levels linked to the economic crisis of 2008, increased anti-immigrant sentiment sparked by Arizona State Bill 1070 that sought to give state police the authority to check the legal status of suspected undocumented people, increased federal spending to secure the Arizona border, and new deportation strategies that were initiated to deter multiple crossing attempts (De León in press; Slack and Whiteford 2011). Recent apprehension statistics (see Table 1 ), a notoriously problematic measure of undocumented migration (Andreas 2009:85-112), suggest that border crossing is at its lowest level in decades. Despite this slowing of migration and the fact that the Tucson Sector is now one of the most heavily monitored regions with the highest fatality rate, Arizona continues to be the preferred crossing point for those who would rather risk the desert than attempt to cross elsewhere along the border where drug cartel violence toward migrants has been escalating (Slack and Whiteford 2011:11). Recent research by Slack and Whiteford (2011) suggests that increased attacks against migrants, high death rates, and anti-immigrant sentiment have done little to deter those still desperate enough to undertake an Arizona crossing in hopes of finding work in a failing and hostile U.S. economy. Others have shown that deportation programs such as the Alien Transfer and Exit Program may be transporting people to Sonora where crossing the desert is the only option (De León in press).

This analysis centers on the act of crossing from Northern Sonora into Arizona. It is, however, important to highlight that undocumented migration is a complex process that extends far beyond the border region. There are key planning stages and social networks involved, which often include contracting a coyote from a person's home community (usu. through kinship networks) and relying on money from relatives already in the United States to pay for the cost of transport (Spener 2009:166-171). Spener's (2009) work on the relationship between coyotes and migrants in south Texas provides insight into both the complexities of the human smuggling business and the strategies that people use to find a reliable guide. Although Spener and others (e.g., Parks et al. 2009) have shown that in many instances coyotes are important resources for undertaking a safe and successful crossing, these analyses have not focused on Arizona where the natural environment and social conditions are more difficult and increasingly more dangerous (Slack and Whiteford 2011:16). In addition, the relationship between migrants and coyotes has been recently complicated by the increasing involvement of drug cartels in human smuggling, coyotes who work in cahoots with bajadores, a rise in migrants from some of the poorest parts of Central America and Southern Mexico who cannot afford to contract more expensive community-based coyotes, and systematic attempts by Bor- 


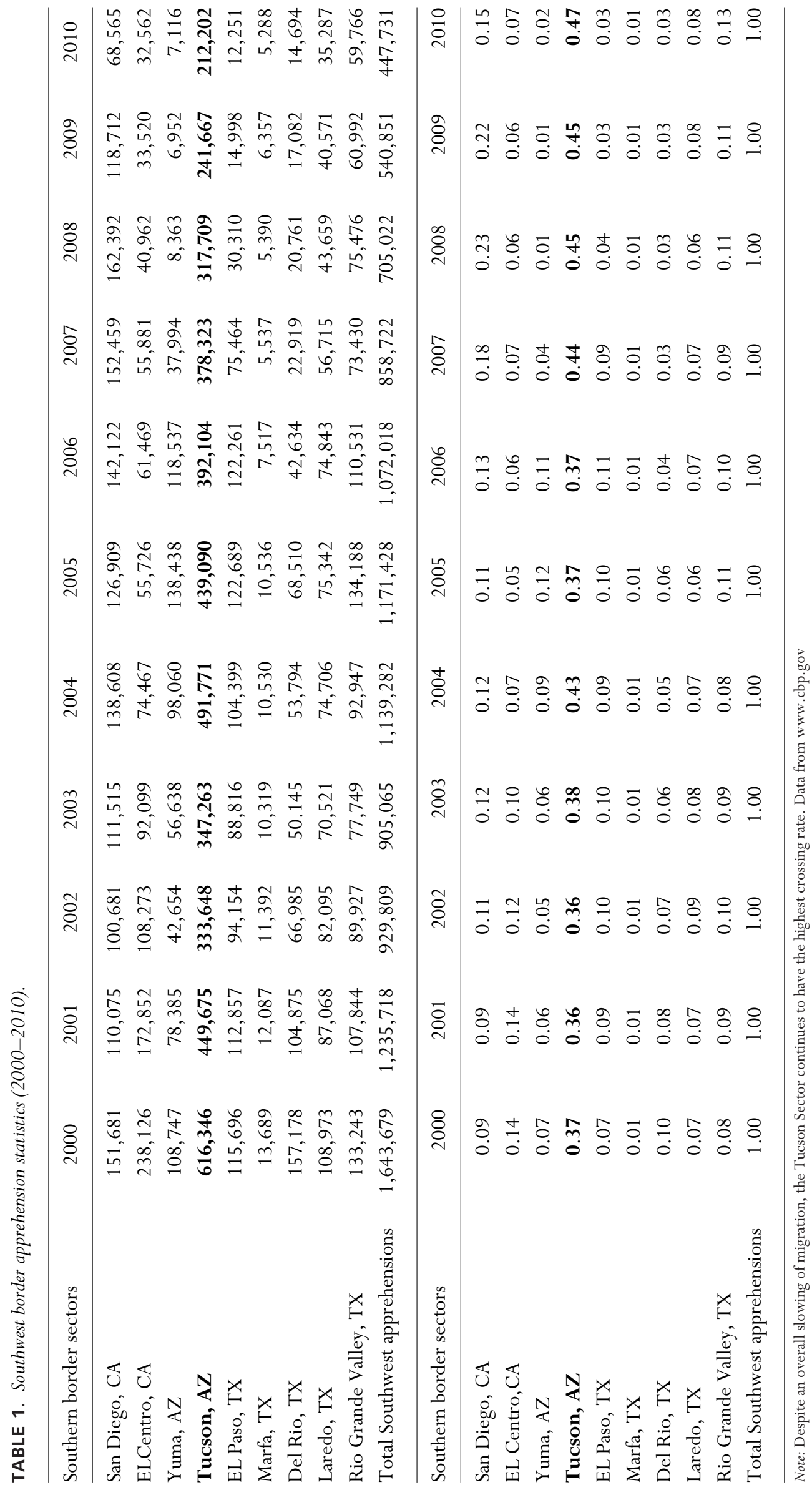


der Patrol to use lateral deportation to separate migrants from their previously contracted coyotes. More than ever before, it is common to see migrants arrive in Nogales (either through lateral deportation or by choice) and contract a local guide who is more likely to rob or abandon them in the desert.

Given the rising anti-immigrant sentiment currently being felt across the United States, it seems unlikely that comprehensive immigration reform will somehow precede improvements in the domestic economy. Moreover, the strategies of border control that are currently in place will likely continue (or escalate) as we approach an election year when politicians often pander to the recurring public perception held by many that the borders of the United States are "out of control" (Nevins 2002:62-94). This emphasis on border security has long been an effective political smoke screen that diverts attention away from economic and foreign policy issues (Andreas 2009). In 2011, the Obama administration deported 396,906 people, the most in Immigration and Customs Enforcement history (McCombs 2011b). Many of these deportees were nonviolent offenders, people with long histories in the United States, and those brought to the country as children. While visiting Nogales in the summer of 2011, I was struck by the number of people I encountered who had been deported after many years of living in the United States and who were now about to undertake a first desert crossing. This rise in deportations of long-time undocumented residents and young adults raised in the United States indicates that immigration enforcement policies are now creating a new type of undocumented migration stream that is fundamentally different from previous generations in terms of life histories, as well as general awareness and preparedness for a desert crossing. My focus on the relationship between migrants and the meager tools at their disposal to survive the desert thus has important implications for understanding the day-to-day experiences of the thousands of people who, despite the current U.S. economic crisis, are still attempting to cross the desert (see Table 1) and how their experiences are linked to and continuously shaped by broad-scale forms of immigration enforcement policy. The hypersuffering that now characterizes the crossing process is likely to continue even once the U.S. economy improves and migration flows increase, suggesting that for the next several years, hundreds of thousands of people will continue to enter the desert and experience many of the difficulties described in this article.

\section{MIGRANT MATERIAL CULTURE}

As the PTD strategy began to shift undocumented migration toward the deserts of Arizona in the 1990s, the human smuggling industry in Northern Mexico grew to deal with the influx of migrants to the region. Sleepy agricultural towns such as Altar soon became major staging areas for hundreds of thousands of border crossers who arrived each year. Subsequently, coyotes, vendors, and local manufacturers began to capitalize on migrants who needed guide services, tem- porary housing, food, and equipment. In Altar, smuggling has become a major industry, and many outdoor vendors and convenience stores now specialize in the goods used by migrants (see Figure 3). Crossings are typically chaotic, and people often have very little control over what will happen to them. One of the few things they can control is what they choose to carry into the desert. Vendors exploit migrant fears and anxieties by selling them a variety of goods at elevated prices under the promise that they are essential for a safe crossing. In this case, desperation, folk logic, and predatory entrepreneurism play major roles in shaping consumer decisions about what to purchase. I refer to the complex of smugglers, criminals, vendors, and manufacturers who profit by robbing and selling products and services to migrants as the Border Crossing Industry. This industry and its associated goods are constantly evolving as migrants, smugglers, and vendors attempt to adjust to changes in enforcement practices and surveillance technology.

Over the years, desert crossing has become associated with a material culture that includes a codified set of darkly colored (sometimes camouflage) clothing (see Figure 3), cheaply made sneakers and hiking boots, consumables, and other accessories. Consumables include bottled water, electrolyte beverages, and high salt content foods (e.g., canned tuna and salted crackers). Additionally, people equip themselves with first-aid and utilitarian items such as gauze, pain relievers, and pocket mirrors used to signal Border Patrol in case a rescue is needed. These items are carried in small darkly colored or camouflage backpacks that once filled can weigh upward of 50 pounds. These goods foremost reflect technological attempts to avoid Border Patrol and cope with the dangerous conditions in the desert. However, these items can also create physical and social problems for those who use them. To illuminate the complex (and often-contradictory) aspects of migrant goods, I use a theoretical framework that emphasizes the role of technology, as well as the dialectical and somatic relationships between people and objects. This approach allows for a better understanding of the forces that have shaped migrant technology, the techniques associated with different objects, how these objects "act" in personal and public domains, and how these items come to be embedded with the traces of human suffering. Below, I briefly discuss each of these components of my approach.

Technology is a fundamental aspect of the human condition that is interwoven into the very fabric of our lives and implicated in all forms of cultural development (past, present, and future) (Mackenzie and Wajcman 1999:3-27). Reductionist views of technology have tended to focus either on the tools themselves or their "effectiveness" relative to other technologies (Lemmonier 1986:150). Some of the most innovative studies of techniques (i.e., technology or technical processes) have shown that material objects are but one (and not always necessary [Downing 2007]) element of complex technical systems that also include action and cognition (Lemmonier 1986:147-148). To understand how objects are appropriated and employed in the context 


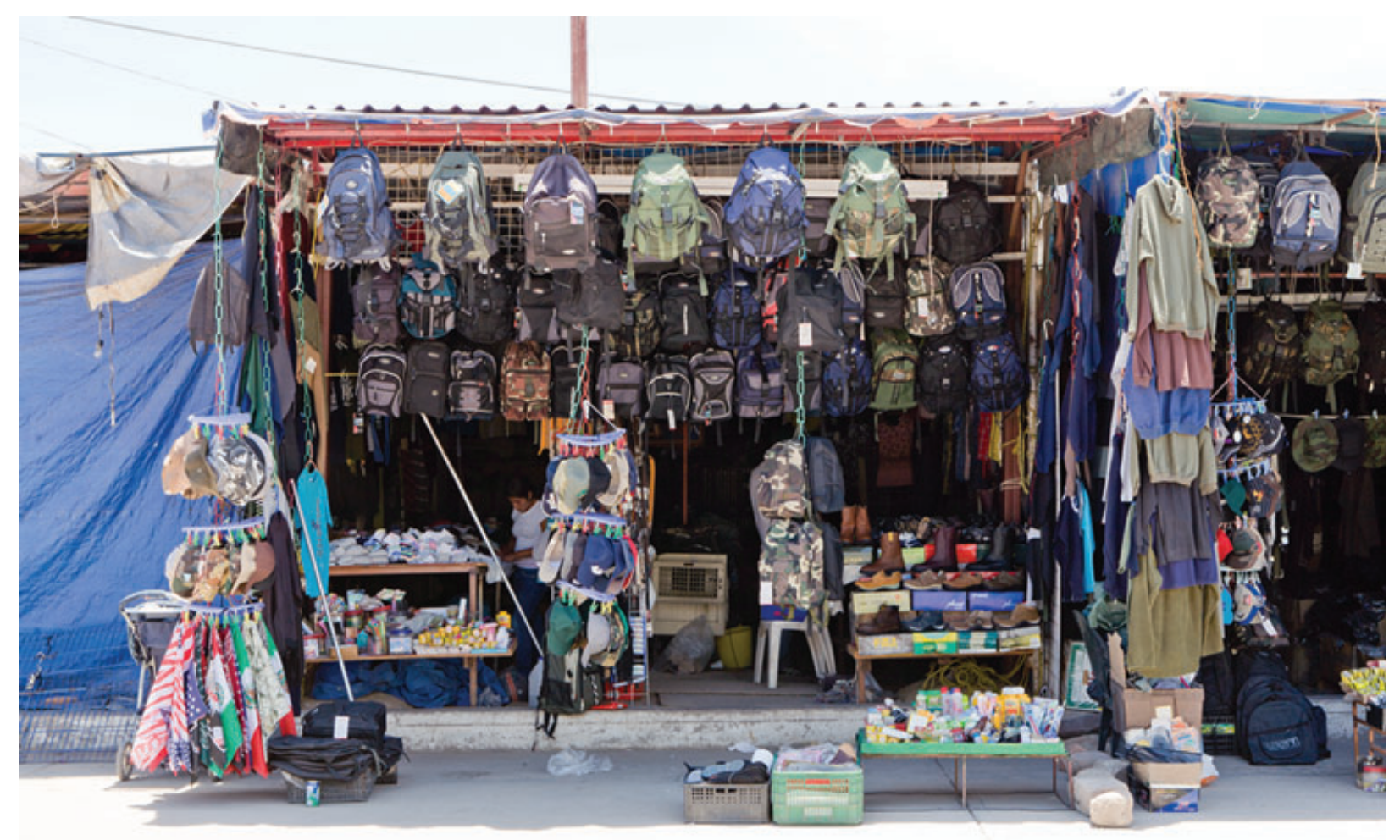

FIGURE 3. Vendor in Altar, Sonora, Mexico that specializes in migrant goods. Photograph by Michael Wells

of border crossing, I draw on technological studies by Alfred Gell (1988) and Bryan Pfaffenberger (1992). Gell points out that minimally "technology not only consists of the artefacts which are employed as tools, but also includes the sum total of the kinds of knowledge which make possible the invention, making, and use of tools" (1988:6). Analyses should thus neither focus primarily on an object's characteristics or its effectiveness at achieving a particular task. Tools cannot be studied in isolation because the knowledge needed to materialize them and employ them in set tasks is fundamentally connected to (and shaped by) the specific social context in which they exist (1988:6). This means that migrant technology may involve commonly found objects such as shoes and water bottles, but their exact use can only be understood in the context of clandestine crossings. Pfaffenberger (1992:497) refers to these distinct contexts of technological activity as sociotechnical systems and argues that they derive from the linkage of techniques (e.g., operational sequences, behavioral patterns, knowledge) and material culture to the social coordination of labor. In this case, the technology and social coordination of labor are directed at helping migrants cross the desert undetected. In addition to contextualizing technological activity to understand how people make decisions about what to use and how to use it, I also draw on theories that focus on techniques of the body (e.g., Mauss 1973; Wacquant 1995) and the relationship between the body and objects (e.g., Bordieu 1977:72-95; Downey
2007:215). Pfaffenberger acknowledges that a key aspect of any sociotechnical system is human action, but his approach is missing a more detailed analysis of the physical techniques involved in object use. My framework gives equal footing to the context and underlying factors that create a sociotechnical system, as well as the bodily techniques involved in the technological deployment of objects in the system. This allows not only for a better understanding of how technologies arise but also the dynamic relationship between objects and the human body. I use Border Crossing Sociotechnical System (BCSS) to refer to the nexus of social, economic, legal, political, and scientific factors that have shaped the BCI as well as the subsequent social processes, technologies, and bodily techniques of desert crossing.

In the following discussion, I demonstrate that the decisions to adopt particular techniques and objects result from the influence and logic of the BCSS. For migrants, it is often the perceived efficacy (i.e., folk logic) that drives the selection of certain types of goods, which can sometimes be ineffective or detrimental. However, my point is not that migrant technology is illogical. As Pfaffenberger points out:

\footnotetext{
That a sociotechnical system develops does not imply that it is a logical system, or the only possible system, that could have developed under the circumstances; social choice, tactics, alternative techniques, and the social redefinition of needs and aspirations all play a role in the rise of sociotechnical systems. [1992:499]
} 
Instead, my focus on technology and its impacts on migrants allows for a better understanding of the social dimensions of how this particular set of techniques is used in the context of crossing and how these techniques are assessed by migrants. Similar to Wacquant's (1995:85) finding that the boxing universe has its own internal logic that may appear irrational to outsiders, the migrant techniques presented here can neither be judged or subject to critical evaluation that blames individuals for using what often appear to be contradictory or somatically damaging practices. Although I am interested in how material culture (mis)functions at the individual level of use and how collectively these goods have the unintended (or at least unwanted) consequence of serving as markers of illegality, my intent is to highlight the dialectical relationship between people and objects and to examine the blurry line between the two (Keane 2006b).

Two decades of research on material culture has demonstrated that objects have social lives (e.g., Appadurai 1986), agency (e.g., Hoskins 2006), and can oppress users (e.g., Latour 1992). My analysis draws on the concept of objectification (Tilley 1996), which posits a dialectical relationship between people and material culture whereby we create objects to improve our capacity as humans and these objects can develop their own autonomy, which may eventually come to oppress us (Miller 2010:59). Whether it is the high fencing and cameras at urban ports of entry that shift migrant streams toward more remote border regions, the motion sensors and unmanned aerial drone planes that detect migrants, or the harsh desert that is used as a geographic deterrent, the bulk of the surveillance and deterrent technologies used along the U.S.-Mexico boundary are inherently oppressive to the flow of undocumented people. Like the panopticon, these specific technologies require very little human input to do their jobs effectively. However, it is not just law enforcement technologies that oppress migrants. The seemingly ordinary objects that have been co-opted for crossings have also come to negatively impact migrants but in more subtle, less obvious manners. This objectification is visible in the ways that migrants try to use objects to improve their personal capacity to avoid detection and survive the desert while simultaneously adopting a uniform set of goods that increases stress on their bodies and publicly marks them as vulnerable and "illegal" to others.

An analysis of the personal and public qualities of migrant material culture allows us to understand both how people conceptualize border surveillance technology and how their adoption of certain goods "makes possible or inhibits new practices, habits, and intentions" (Keane 2006a:193). This framework provides insight into why material culture (e.g., dark clothing) that has negative impacts on people's bodies and social interactions continues to be used by migrants over time. Karen Hansen notes:

The subjective and social experiences of dress are not always mutually supportive but contradict one another or collide. The contingent dynamic between these two experiences of dress gives rise to considerable ambiguity, ambivalence, and, therefore, un- certainty and debate over dress. Dress becomes a flash point of conflicting values, fueling contests in historical encounters, in interactions across class, between genders and generations, and in recent global cultural and economic exchanges. [2004:372].

Focusing on the conflicting role of migrant material culture is fertile ground for improving our knowledge about the social process of border crossing, as well as the embodied experiences of migrants. As part of this analysis, I argue that migrant-specific habitus (Spener 2009:226-229) in the form of routinized physical suffering can be gleaned from detailed studies of migrant artifact classes and how they were used or modified. In particular, I employ the archaeological concept of "use-wear" (i.e., modifications made to objects as a result of usage) to provide a more intimate understanding of the somatic relationship between people and objects. Studies of artifact use-wear and discard show how the repeated patterning of empty water bottles, worn out shoes, and sweat-drenched clothes reflect years of individual and collective suffering in the desert. Migrant habitus is not only represented in the traces of human activity embedded in individual artifacts but also in the long-term systematic use of particular objects associated with the alleviation of suffering that derives from exposure to the desert environment (e.g., pain medication, gauze). In the following sections, I describe three classes of commonly used artifacts (water bottles, shoes, and clothes), highlight the technique and logic behind their use, and document the somatic and social effects these goods have on people.

\section{WATER BOTTLES}

By far the most ubiquitous artifact type found at migrant stations is the water bottle. This is no surprise given that the leading cause of migration-related injuries and death are now linked to hyperthermia (failed thermoregulation caused by exposure to excessive temperature) (GAO 2006:15). Outside of avoiding heat and exposure to the sun (often an impossibility in the desert), the only way to combat this problem is through the continued consumption of water and other hydrating liquids. In no uncertain terms, bottled water is what keeps people alive.

Most of the water purchased by migrants is bottled locally in one of the many plants in Northern Mexico that cater primarily to this transitory population. In Altar alone (population approx. 9,000) there are at least six water bottling plants, all of which produce the typical plastic one gallon rounded jug that is commonly used by migrants (see Figure 4a). Migrants favor this style because its large handle and thick walls make it durable and easier to carry on long walks. This vessel style is not typically used by U.S. water companies, making it easy to distinguish country of manufacture based on bottle shape alone. Prior to 2009, all of the one gallon Mexican bottles were manufactured using either clear or white opaque plastic. For many years migrants either painted these bottles black or fashioned covers out of plastic, burlap, or cloth (see Figure $4 \mathrm{~b}-\mathrm{c}$ ) in an attempt to camouflage the object from Border Patrol. A common 


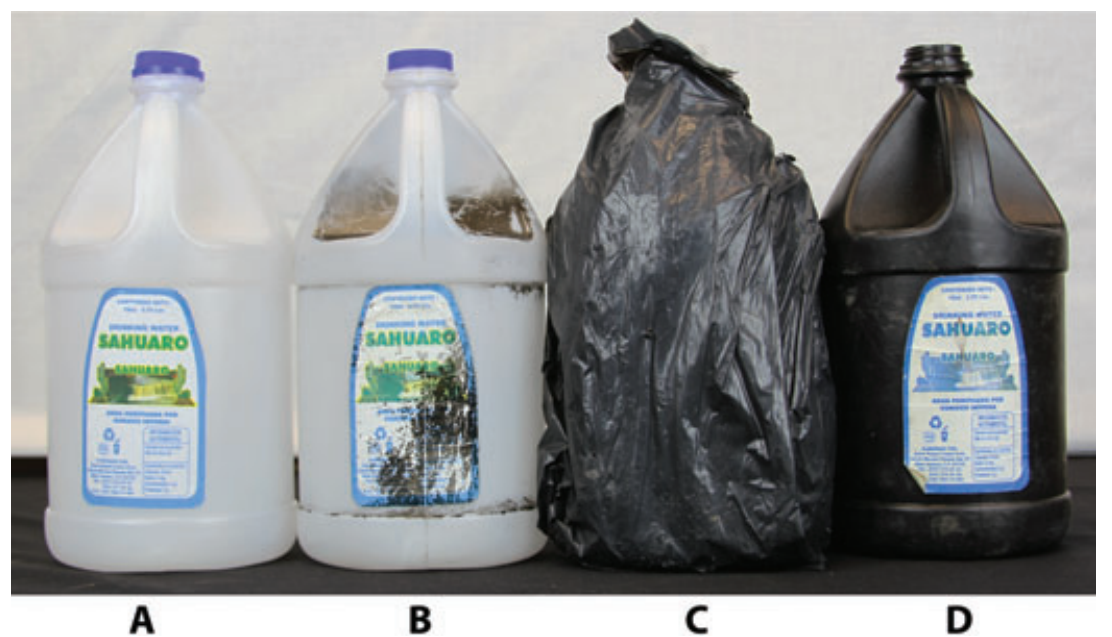

FIGURE 4. A) One gallon white bottle. B) Bottle with plastic cover. C) Bottle that was once painted black with shoe polish. D) Black plastic bottle

assumption is that white bottles are a disadvantage. As one person stated: "We got caught on the first night of our trip because Border Patrol saw the light reflecting off of a water bottle." Toward the end of 2009, companies began to produce one gallon bottles out of black plastic (see Figure 4d), a sign that technological changes at the factory level were the direct result of migrant preferences. However, agents working on the ground primarily rely on sign cutting (i.e., foot tracking), ground sensors, infrared cameras, and sound to locate people, suggesting that it is unlikely that darkly colored bottles provide a strong tactical advantage. The insistence by migrants (and border vendors) that camouflaged bottles help you avoid detection probably reflects a combination of people's lack of understanding about current surveillance technology, as well as entrepreneurial attempts to capitalize on migrant folk logic. In addition to specialized color and shape, many company brand names overtly target migrant consumers and their religious beliefs. For example, one company in Altar is called "Santo Niño de Atocha" and their label features a drawing of the Latino version of the Christ child believed to assist pilgrims on dangerous journeys (Thompson 1994; see Figure 5). To an observer familiar with the BCI (incl. Border Patrol), the shape, color, and labels on these bottles are easily recognized as both being manufactured in Northern Mexico and linked to undocumented migration.

\section{Technique and Logic}

Although human water needs range widely depending on metabolism, climate, diet, clothing, and activity level (Sawka et al. 2005:31-33), estimates of the average U.S. Adequate Intake (AI) (i.e., the level of daily water consumption needed to prevent the deleterious effects of dehydration) are approximately 3.7 liters and 2.7 liters for middle-age men and women, respectively (Institute of Medicine 2004:73). ${ }^{3}$ However, this AI is likely insufficient for desert environments where studies have shown male soldiers losing an average of 4.9 liters of water a day from sweating alone
(2004:4-11). Some postulate that active adults in warm climates have a daily water need of six liters (Sawka et. al 2005:32), a conservative estimate for those doing intense desert hiking. If we use six liters as a minimum AI for adults walking several miles a day during hot summer months, a person would need to consume approximately 1.6 gallons a day to prevent dehydration. If someone walks for three days, which is the approximate time it takes to get from the border to one of the common rendezvous locations in southern Arizona (e.g., Three Points) (see Figure 2), they minimally need to carry 4.8 gallons. A gallon of water weighs 8.35 pounds, which means that someone carrying four gallons starts their trip with 33.4lbs of liquid. This weight would be augmented by food, extra clothes, and other supplies. Based on my observations and interviews, the maximum amount of water an adult can carry is four gallons, with many opting to bring between one and two (see Figure 6a).

Migrants typically never carry enough water to sustain themselves on a multiday crossing, and this is influenced by several factors. First, many crossers are unfamiliar with desert environments and greatly underestimate how much water they will need to consume to avoid hyperthermia or dehydration. This is often exacerbated by conflicting information they may be told by their coyote (who almost always underestimates the actual distance that will be walked), stories they have been told by other migrants who crossed with little water, or a person's inability to purchase water. The amount of water a person carries is also influenced by their physical (in)ability to carry multiple gallons, the size of their backpack, and how much other gear they are carrying (see Figure 6b). In an excerpt from a typical interview with a person preparing to cross, they talk about the difficulty of carrying water:

I'm bringing one gallon of water. I know it is not enough, but water is really heavy. I can't carry more than one gallon. Look at my bag [points to a small duffel bag] ... I don't want to drink too much water before I leave... I don't want to get a cramp... I 


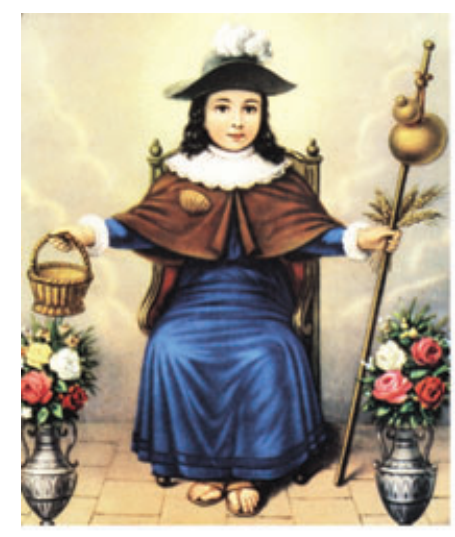

A

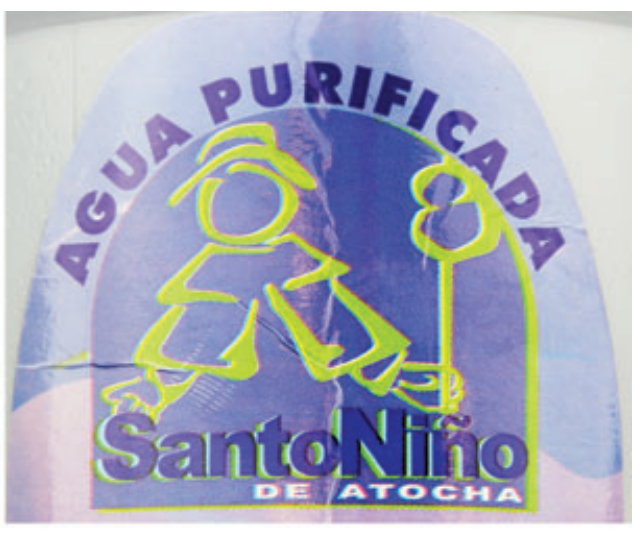

B

FIGURE 5. A) Santo Niño de Atocha is a Latino version of the Christ child who is thought to assist travelers on journeys. B) A bottle from the Santo Niño de Atocha factory in Altar, Sonora, Mexico

just take little sips of my bottle and hope that I find more water along the way if I run out.

Those who find gallon bottles too heavy or expensive will opt for smaller sizes (ranging from 500 milliliters to 1.5 liters). It is common to see people traveling with less than one gallon of water in their packs, and the high density of small bottles found at migrant stations suggests that this is a widespread trend.

\section{Somatic Impacts}

Having insufficient water for a crossing inevitably creates physiological stress, and the majority of people I interviewed who spent more than a day in the desert described suffering from various effects of hyperthermia:

\footnotetext{
I thought I was going to die out there ... I couldn't take it. My heart was pounding and I started to see things. I was delirious. I was hallucinating. I was looking at the trees but I was seeing houses and cities all around me... I would stop and take a small drink of water but five minutes later I would see things again . . . I only brought a gallon of water with me. [Raul, 36 years old]
}

Additional water sources for those who run out are limited in the desert. Although some humanitarian groups maintain permanent water tanks and water drop locations for migrants, these sites are few and far between. Those who run out of water often rely on stagnant ponds or bacterialaden water tanks used for livestock, if they are "lucky" enough to encounter one (see Figure 7a). This practice is archaeologically visible via use-wear on refilled bottles (see Figure 7b). Moreover, many commented that drinking this water causes intestinal illness and increased dehydration:

We crossed with another man who was 62 years old. He couldn't handle it. He drank some water from a cattle tank that made him sick. Well, we all drank it but he got an infection. The water had little animals swimming in it but we were so thirsty. ... He started vomiting and had diarrhea so we took him back into Mexico.

Even if you have enough water to stay hydrated, it may heat to a temperature that renders it virtually undrinkable. During the summer of 2010, as part of the UMP field school, University of Washington undergraduate student Steven Ritchey conducted an experiment to test the temperature differential between white and black bottles. He filled both types with water and exposed them to direct sunlight over the course of a typical summer day. Measurements of the internal temperature of the water in each bottle were taken at one hour intervals, along with the corresponding external air temperature (see Figure 8). The results showed that within the first hour, the black bottle's temperature eclipsed both ambient temperature and the white bottle. By 12:30 p.m., the temperature differential between bottles reached 15 degrees $\left(\right.$ black bottle $=121.8^{\circ} \mathrm{F}$, white bottle $=$ $\left.106.8^{\circ} \mathrm{F}\right)$. The black bottle would eventually heat to 126.3 ${ }^{\circ} \mathrm{F}, 6.3$ degrees higher than the recommended temperature setting for a domestic water heater. Drinking hot water raises a person's core temperature forcing the body to expend additional energy to cool the hot liquid. This can increase exhaustion levels even if the liquid is consumed while resting. Additionally, gulping hot water in the desert is not only unpleasant but also sometimes physically difficult.

\section{SHOES}

Because of their close connection to the body and their ability to maintain shape even when the wearer is absent, shoes are an artifact class whose physical properties are strongly tied to those who once wore them. For example, in museum contexts they are often used as "stand-ins" for those who cannot be physically present. However, making shoes metonyms for people or their embodied experiences can be ethically questionable (Jones 2001) and theoretically reductionistic. I argue that the hundreds of shoes recovered by the UMP that belonged to women, children, and men are an important artifact class. However, instead of functioning as metonyms for migrants, these objects provide phenomenological insight (via use-wear) into the dialectical relationship between people (in this case their feet) and the desert. 


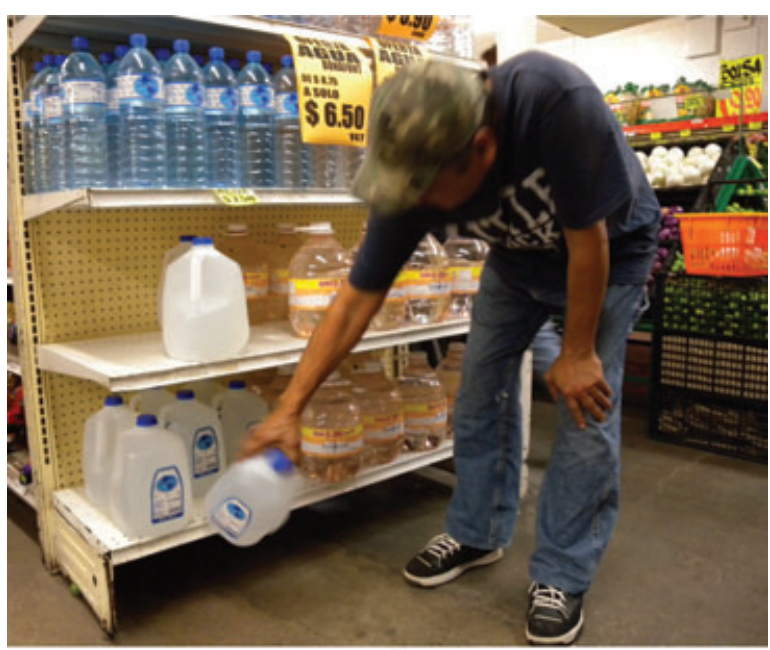

A

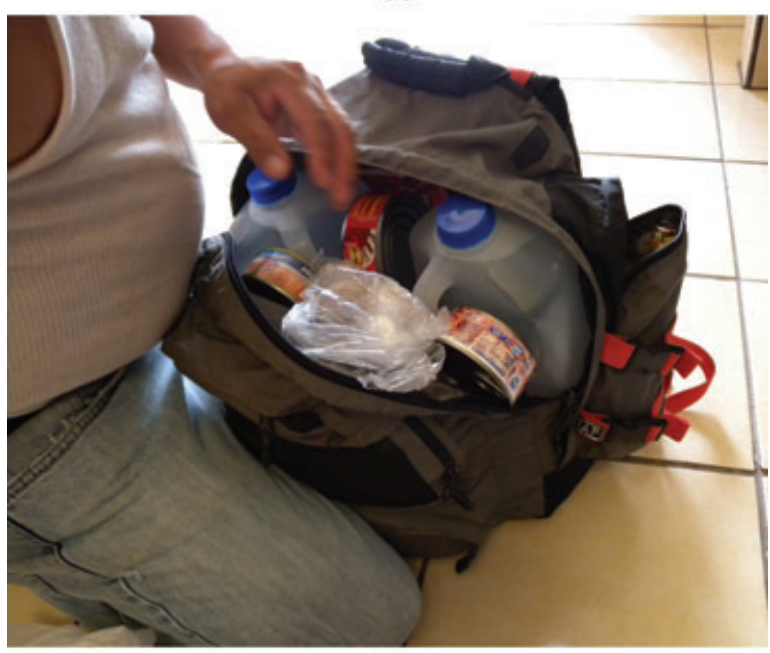

B

FIGURE 6. A) Shopping for water. B) Packing a backpack

The shoes most commonly worn by migrants are inexpensive Chinese- or Mexican-made sneakers, usually replicas of higher priced U.S. models (see Figure 9). These shoes are often ill-fitting, poorly constructed, and generally not wellsuited for rugged desert hiking (see Figure 10). They offer little ankle support, have hard rubber bottoms that easily wear through, and have soles that frequently detach from their leather or plastic uppers. It is common for people to carry an extra pair of shoes (in case their first pair breaks) and super glue for ad hoc repairs. Sneakers are common, but those who cannot afford them or who choose to wear something more familiar will attempt to cross the desert in styles including cowboy boots, dress shoes, cheap hiking boots, and traditional sandals.

\section{Technique and Logic}

Most migrants cannot afford high-end hiking boots, but their preference for sneakers is not a simple economic issue. Individuals may be familiar with hiking boots, but opt for sneakers because they have never worn hiking boots, they believe that sneakers are more appropriate for the desert, or they choose to wear the shoe style they think will both get them through the desert and stylistically help them blend in once in the United States. It is not uncommon to see Mexican and Central Americans crossing the desert with fresh haircuts and new sneakers. Many undocumented migrants assume that the best way to avoid detection is to "not look poor," a strategy that can backfire. I once observed a Mexican immigration official board a bus in Chiapas and single out and remove a group of Central American migrants whose new wardrobes, fresh haircuts, and shiny sneakers caused them to stand out against the rest of the passengers who appeared to be working-class, underdressed Mexicans. Although sneakers may be the most accessible and culturally preferred type of footwear for migrants, their use in the desert has harmful impacts on people's feet.

\section{Somatic Impact}

Friction blisters are subdermal pockets of fluid caused by forceful rubbing. After hyperthermia-related injuries, blisters on feet are the most common physical trauma experienced by migrants (see Figure 11). During normal longdistance hiking these injuries can be caused by poorly conditioned feet, ill-fitting shoes and socks, improper footwear, heat, and moisture, all of which are typical conditions for border crossers. Migrant blister problems are exacerbated by cheaply made shoes (esp. if they are not "broken in"), a

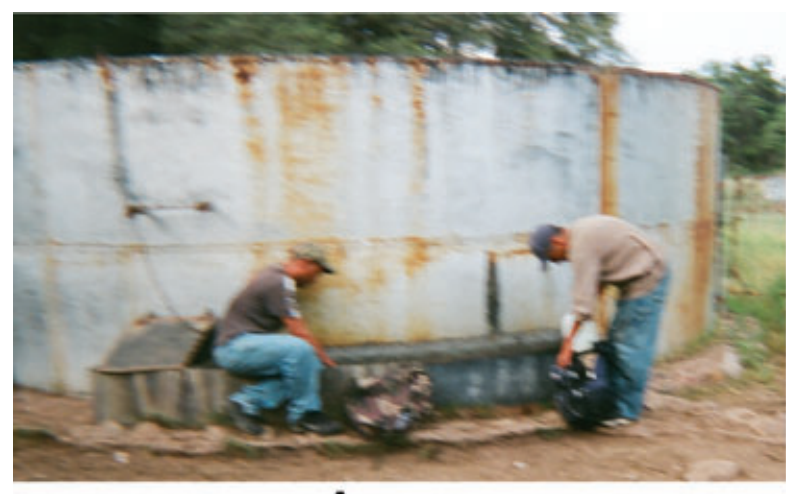

A

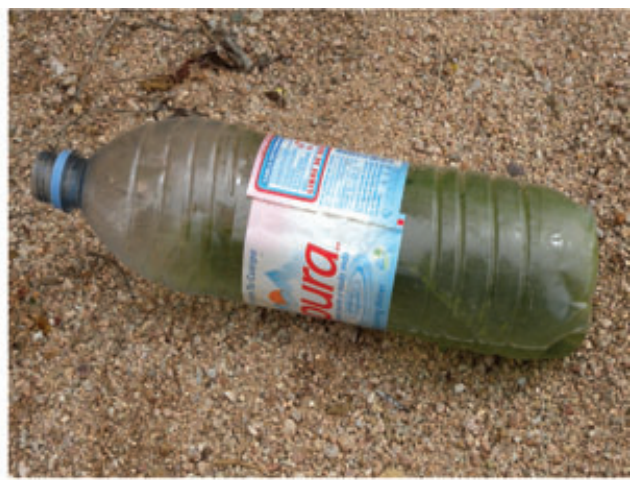

B

FIGURE 7. A) Filling up bottles at a cattle tank. B) Recovered bottle filled with green cattle tank water 


\section{Water Bottle Temperature Comparison}

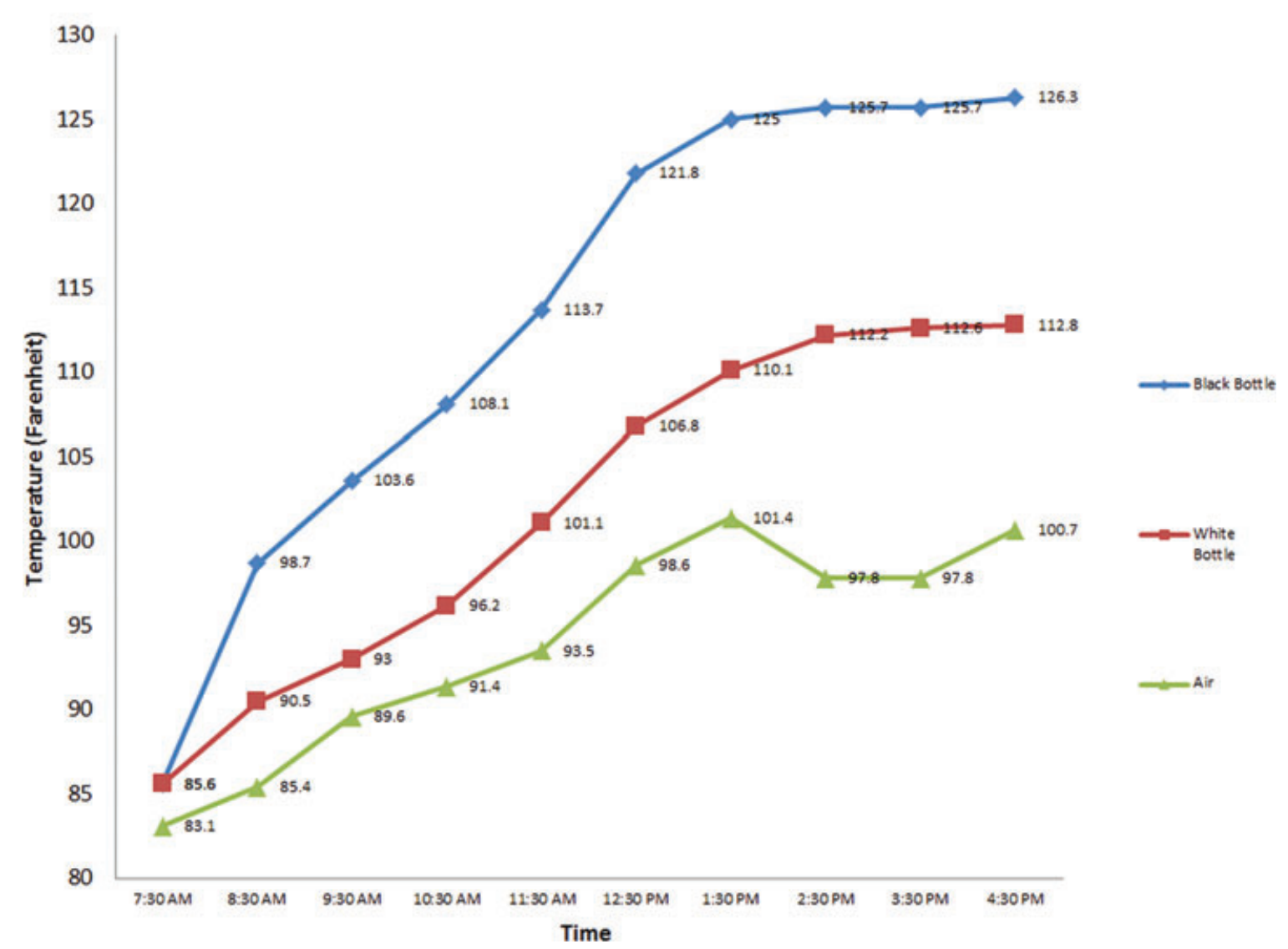

FIGURE 8. Results from an experiment comparing the water temperature in white and black plastic bottles (Courtesy of Steven Ritchey)

person's failure to recognize and adequately treat the early stages of a blister, and unhygienic desert conditions that can lead to infection. Migrants who employ a guide are often at the mercy of their coyote who typically dictates if and when the group can stop and rest. Additionally, Border Patrol's relentless pursuit of migrants by air and land, combined with a person's desperation to cross the border, may lead people to ignore foot and other injuries until they can no longer walk. By the time people get a chance to change their shoes, socks, or apply first-aid, their blisters may have become severe. Indirect evidence of this foot trauma is visible archaeologically in the bloody socks, gauze, and worn out shoes (see Figure 12) that are often recovered at migrant stations located several days walk from the border. Those who develop severe blisters sometimes only stop walking once they are captured by Border Patrol or when their feet literally give out. This extreme walking behavior is logical if one considers that many who undertake crossings are escaping some of the most impoverished communities in Latin America (and beyond) or trying to return home to their families in the United States at any cost, even death. I've witnessed this desperation when I have encountered people in the desert who were suffering from extreme dehydra- tion, excruciating blisters, and life-threatening injuries but had to be thoroughly convinced to go to the hospital to avoid impending death.

\section{CLOTHING}

Recent anthropological studies of clothing have focused on the dialectical relationship between people and the objects with which they adorn their bodies (Miller 2010:12-41). Moving beyond previous semiotic studies of clothing that tended to emphasize the ways in which these items represented differences (e.g., class), these new analyses highlight the active and substantial role that dress plays in creating and shaping peoples experiences and determining what constitutes the self (e.g., Banerjee and Miller 2003). For example, in her study of sarongs in Eastern Indonesia, Catherine Allerton (2007:25-37) found that they are intimately tied to the wearer's body and bodily substances while also projecting messages that are interpreted by the outside world. Here I demonstrate a similar pattern whereby the clothing adopted by migrants for clandestine crossings impacts their bodies and simultaneously sends messages to others about their social and juridical status. 


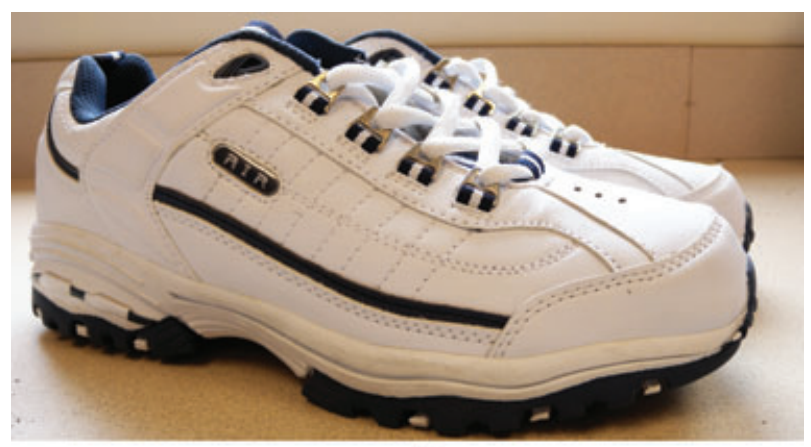

A

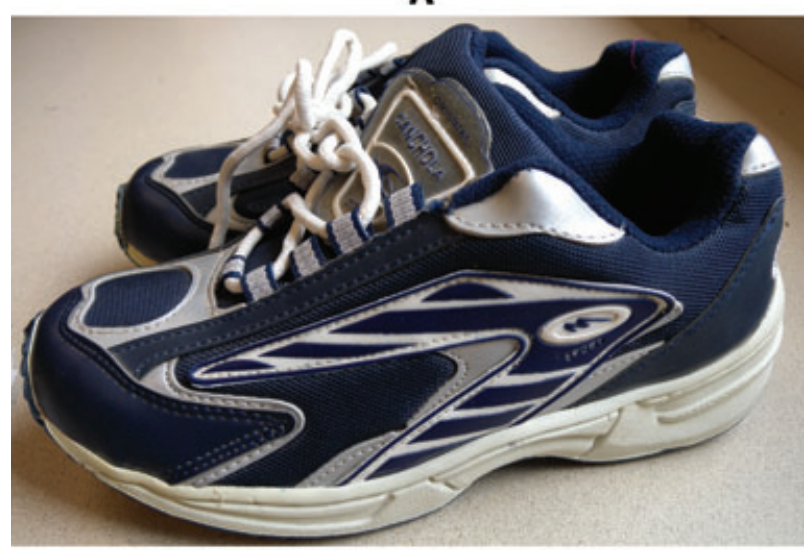

B

FIGURE 9. New pairs of men and women sneakers typically worn by migrants

Migrants typically wear darkly colored clothes, usually black T-shirts, dark denim jeans, and dark sweatshirts (see Figure 13b). These items either come from a person's wardrobe or are bought from border vendors. Unlike specialty hiking clothes that are designed with lightweight fabric for optimal ventilation and quick drying, most migrants wear clothes constructed with thick cotton, synthetic fibers, or denim. These clothes are heavy, absorb heat and moisture, and are not well-suited for desert environments or hiking. This apparel is usually supplemented with dark socks and shoes, as well as black, blue, or camouflage backpacks (see Figure 13a).

\section{Technique and Logic}

Similar to black bottles, dark clothing is thought to be an effective form of camouflage, especially when walking at night or when resting in shaded areas during the day. However, as previously noted, most of the methods Border Patrol uses to detect migrants rely on remote sensing, signcutting, and infrared. A description of the infrared thermal imaging used by Border Patrol suggests that dark clothing is useless against (and may actually assist) this surveillance technology:

\begin{abstract}
All objects that are not at absolute zero temperature emit various types of electromagnetic radiation including infrared. The hotter an object gets, the more infrared radiation is emitted.... Blacker colors and duller surfaces usually have a higher emissivity and radiate infrared energy more effectively.... Due to their own levels of infrared heat energy, people are easily seen 24 hours a day. [Mesenbrink 2001]
\end{abstract}

\section{Somatic Impacts}

Dark clothes absorb more heat, which can raise a person's core temperature and increase the rate of dehydration and heat-related exhaustion. Compounding the issue of heat absorption is the added weight of thick insulated clothes and a heavy backpack along with the low moisture permeability of material such as denim. Together, these factors contribute to increased physiological strain in the form of more wetted skin, higher skin temperatures, and greater general discomfort. This stress is often seen in the recovered clothes and backpacks that emit intense perspiration odor and display large, crystalline sweat stains.

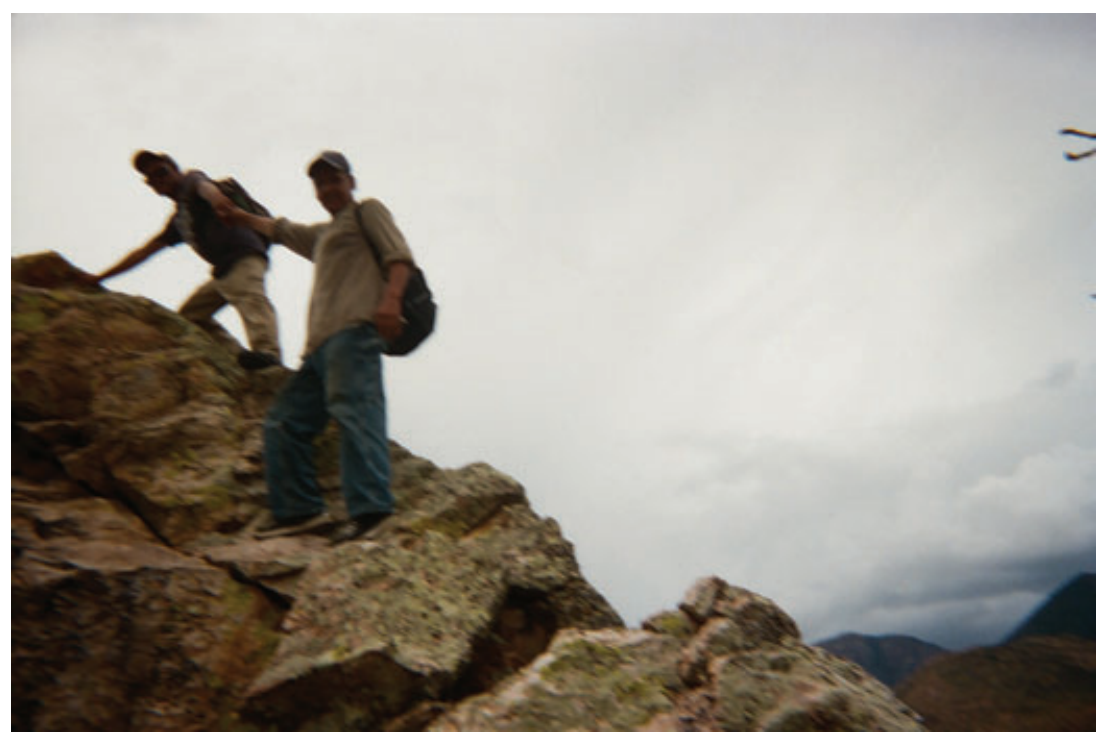

FIGURE 10. Climbing over rocky terrain in sneakers 


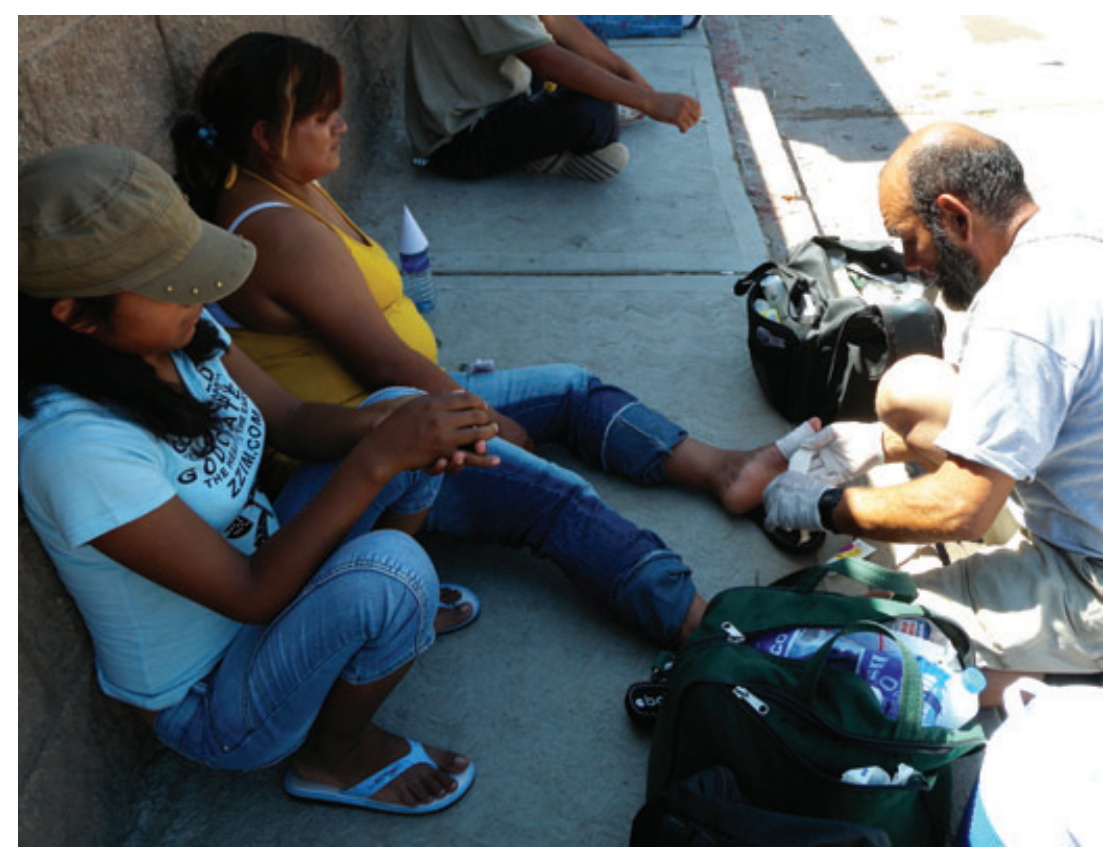

FIGURE 11. A woman having her blisters bandaged after a failed desert crossing

The physical stress caused by wearing dark clothes impacts people individually, but for migrants as a group these clothes create the unwanted signal that a person is a border crosser. Border Patrol agents I have spoken with commented that when using remote cameras or visual spotting techniques they can easily distinguish among hikers, narcotraffickers, and migrants based on a combination of phenotype, clothing style, backpacks, water bottles, and behavior. In essence, walking through the desert wearing dark clothing arouses suspicion. My personal tendency to wear dark clothes and a large backpack while conducting archaeological surveys has repeatedly caused me to be dusted by Border Patrol helicopters and stopped and questioned by agents on the ground. ${ }^{4}$ It is not just agents who read signals from migrant clothing. Both the bajadores who assault migrants in the desert and the criminals who prey on recently deported people at ports of entry use clothing as an indentifying characteristic when selecting their victims (De León in press).

\section{DISCUSSION}

Despite repeated use over many years, the migrant techniques and goods described here are at best minimally effective at helping someone avoid detection and at worst somatically and socially injurious. In essence, the paradox of objectification (Miller 2010:59) is visible in the contradictions created by the reliance on particular types of water bottles, shoes, and clothing that often do more harm than good: the black water bottles that marginally help someone avoid being seen while simultaneously heating up its life-saving contents to an almost undrinkable temperature; the cheap sneakers that migrants assume will be suitable for hiking but eventually rip apart while traversing a rocky and thorny ter- rain, but not before causing excruciating blisters; the dark clothing that is supposed to provide camouflage but is useless against Border Patrol's sophisticated technologies and instead raises the body's core temperature and helps speed up the dehydration process. Close inspection of these objects shows how each betrays their user in different ways. When examined collectively as an archaeological assemblage that goes back as far as the 1990s, a pattern of use-wear emerges that is indicative of routinized and intense human suffering resultant from millions of systematic attempts to overcome institutionalized enforcement practices. If we look at migrant material culture from the perspective of those who encounter border crossers and read the messages encoded in their quasi-uniforms, we see that the clothes, water bottles, and cheap sneakers further betray people by broadcasting their vulnerability to those seeking to either apprehend or assault them.

In their seminal paper on border crossing, Singer and Massey argued that border crossing is a "well-defined social process whereby migrants draw upon various sources of human and social capital to overcome barriers erected by U.S. authorities" (1998:562). People accrue migration-specific capital (i.e., the human and social capital gained from the crossing experience such as where, when, and how to cross) during each attempt, and as this capital increases so does one's likelihood of success (1998:569). Others have since confirmed these findings (e.g., Spener 2009). The question then arises: If migrants accumulate knowledge during each crossing attempt, why do the seemingly negative or ineffective techniques described here continue to be replicated? The answer to this question is not straightforward and requires a dissection of the many factors that shape the BCSS. 


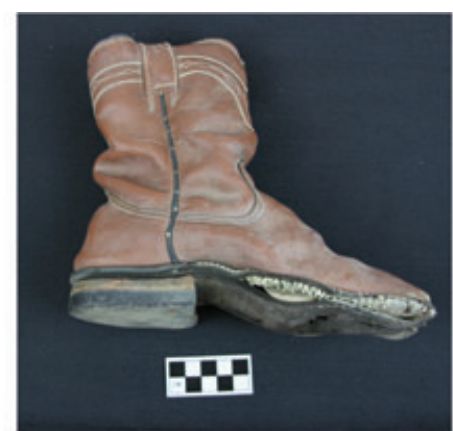

A

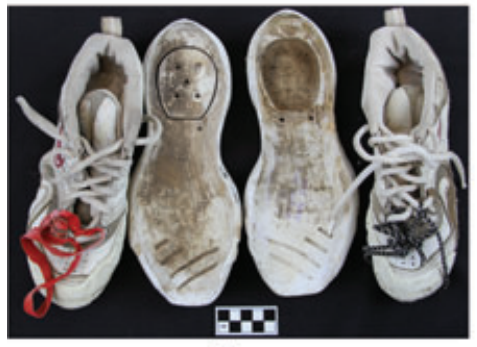

C

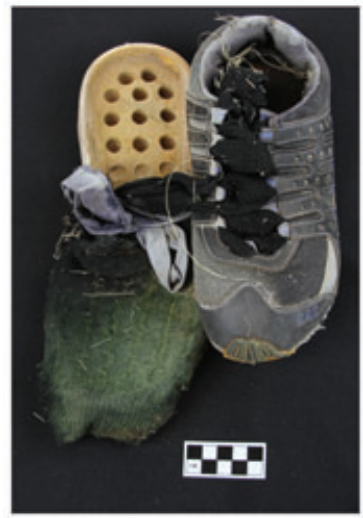

E

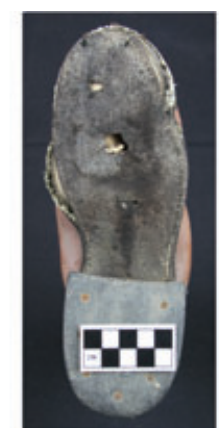

B

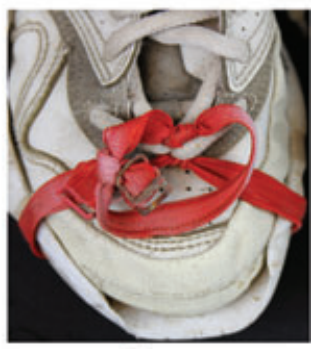

D

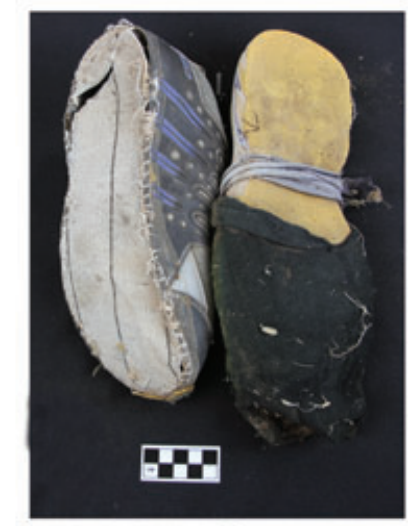

$\mathbf{F}$
FIGURE 12. Shoes with use-wear. A-B) A child's cowboy boot with hole worn through the sole. C-D) A woman's sneaker with detached soles. A red bra strap was used to refasten the two parts. E-F) Shoe with detached sole that the user has attempted to re-connect with a sock and binding from a t-shirt.

Border crossers, even first-timers, are often aware of the general obstacles involved in the process. Still, this phenomenon is chaotic and rife with physical and emotional difficulties that can make focusing on the minutia of material culture quite challenging. The tendency to downplay or ignore material culture in this setting relates to what Miller calls the "humility of things":

Objects are important, not because they are evident and physically constrain or enable, but quite the opposite. It is often precisely because we do not see them. The less we are aware of them, the more powerfully they can determine our expectations, by setting the scene and ensuring our appropriate behavior, without being open to challenge. They determine what takes place to the extent that we are unconscious of their capacity to do so. [2010:50].

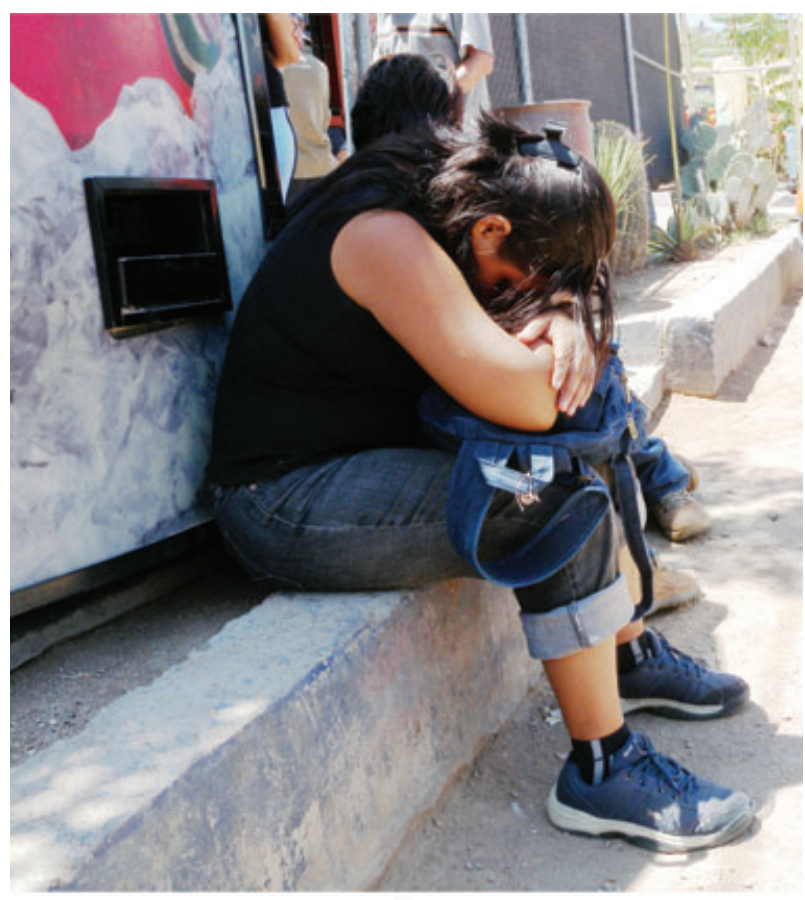

A

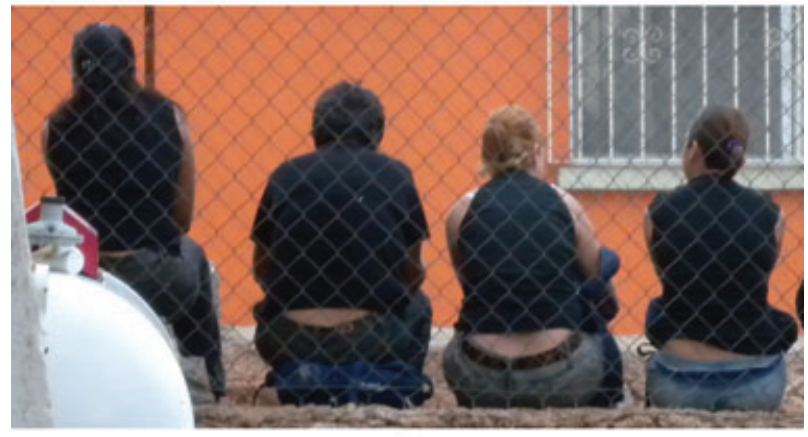

B

FIGURE 13 A) and B) Migrants wearing dark clothes

Among those facing injury and death, the failure to recognize the negative impact of black water bottles or cheap sneakers is not only excusable but also expected.

Additionally, the ineffectiveness of different types of techniques can be subtle and difficult to disentangle from the general chaos, violence, and suffering of border crossing. Migrants already expect the process to be miserable, and the fact that one technique might add additional discomfort can be easily overlooked. Moreover, the ephemeral nature of border crossing communities and the diversity of individuals involved in the process (e.g., migrants from different ethnic and economic backgrounds) means that there is often little regulation of folk knowledge and a great deal of mythology about what the process is like. One only needs to spend an hour talking with a group of recently deported migrants to hear a wide range of crossing techniques that range from "rational" (e.g., drinking a lot of water) to preposterous (e.g., a person once told me he almost evaded Border Patrol in the dark by walking on all fours and pretending 


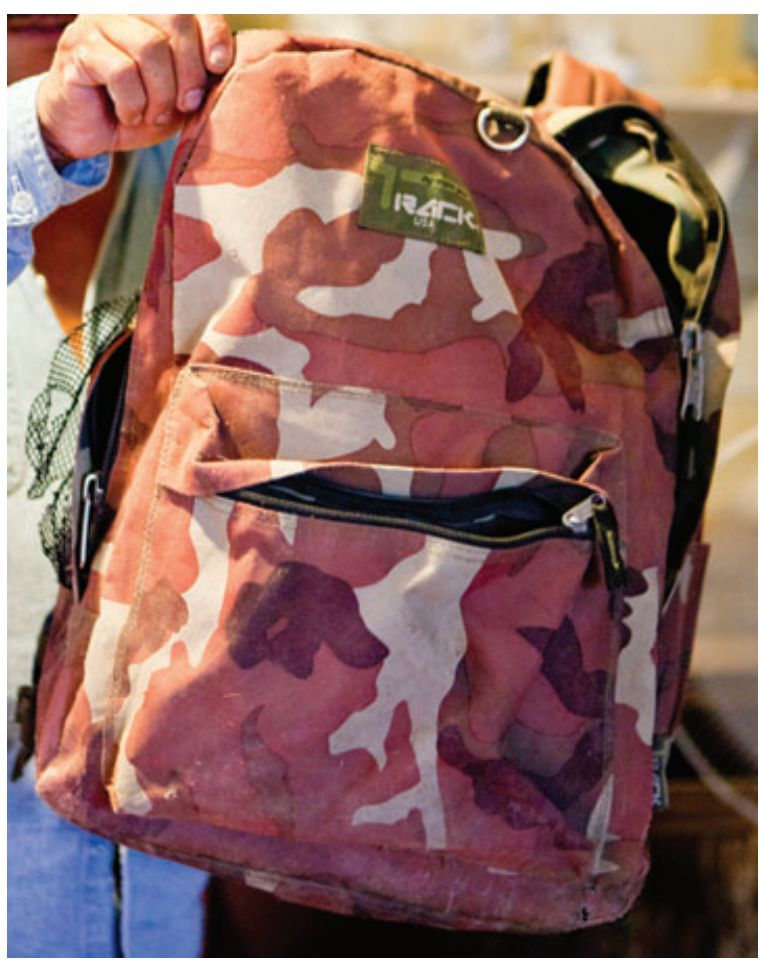

FIGURE 14. Victor and his backpack. Photograph by Michael Wells

to be a wild animal). Migrants often lack the means to critically evaluate and test different techniques in the desert, and many will often accept that certain technologies are effective (even if they are not) because they see others using them. The BCSS has its own internal logic that is difficult to critique from within the system. Furthermore, the BCSS is not strongly regulated, and misinformation can both easily be incorporated into and perpetuated by the system. A migrant's crossing success is strongly determined by tenacity and luck (Cornelius et al. 2008), which means many have been able to cross despite their use of seemingly harmful techniques.

\section{CONCLUSION}

This article provides insight into the complexities and conflicts of the material culture and techniques that hundreds of thousands of undocumented migrants rely on each year during dangerous border crossings. This material culture has been shaped by 20 years of institutionalized enforcement practices that have funneled people toward the Sonoran Desert, by the human smuggling industry that profits by responding to and overcoming changes in border security strategies, and by the migrants who for many years only needed to evade Border Patrol and survive the lethal desert gauntlet before being welcomed through the literal and figurative backdoors of low-wage labor markets in the United States. The recent rise in deportations and state-based antiimmigration laws directed at policing the undocumented labor force suggest that things are going to get worse for migrants before they get better, and it remains to be seen whether the rate of border crossings will rise if and when the U.S. economy improves. Although apprehensions are at an all-time low, there are still thousands of both impoverished migrants and recently deported long-time undocumented residents who are entering the desert. This dynamic nexus of suffering, politics, economics, and contradictions continues to shape the BCSS today.

My analysis has focused on the dialectical relationship between migrants and their material culture to highlight that these objects and technology: (1) are fundamentally connected to (and shaped by) the BCSS, (2) are formalized and have a clear technological purpose, (3) are logical within the context of the BCSS but often have conflicting somatic impacts, and (4) emit social messages at every stage of the crossing process. I have shown that people's perceptions about the functionality and efficacy of particular goods are often in direct conflict with the social and somatic impacts associated with the use of those of objects. In many instances, migrant material culture is profoundly oppressive and often runs counter to the goals of avoiding detection and surviving the desert. However, migrants have limited economic means to purchase equipment that would make their trip more bearable. People make conscious decisions to purchase and use certain goods because they are relatively affordable, they are rational based on the collective knowledge associated with the crossing process (influenced by vendors, coyotes, and previous migrants), and the sometimes dysfunctional nature of different techniques is camouflaged by a host of factors that make the crossing experience a chaotic setting where no one particular object or behavior will ensure success. Many have either been caught or lost their lives because of ineffective or harmful techniques, but millions of others have successfully crossed with little water and cheap sneakers.

I have focused on the techniques, as well as the oppressiveness of migrant material culture. My intent has not been to provide evidence that all undocumented migrants are easily identifiable based on what they wear and carry but, rather, that in the Sonoran Desert, one can expect to find a relatively uniform collection of material culture that reflects a specific group's set of techniques used to overcome border enforcement. To declare that migrants can somehow be identified solely on shoes or clothes foolishly ignores the complex and dominant role that racial profiling plays in border enforcement. Simply put, the primary measure Border Patrol uses to identify suspected undocumented migrants is phenotype. You only need to ask "documented" Latinos who live in southern Arizona what arouses suspicion at immigration checkpoints to understand that one's skin color, last name, and accent supersede clothing or shoes. The study presented here should also not be seen as an attempt to offer insight into how to avoid detection. No technology that is readily accessible to impoverished border crossers could ever hope to match the level of sophisticated machinery that is used to detect and capture people. The best that any migrant technique can hope to accomplish is assuage some of the 
suffering experienced in the desert and possibly help someone avoid an untimely death. Although I have highlighted some of the conflicts associated with migrant techniques, future research will need to address the contradictions of Border Patrol surveillance technologies that are relatively ineffective in "deterring" people from migrating but highly successful in making the crossing process more miserable and dangerous.

Intensified border enforcement, increases in violence associated with border crossing, and more punitive measures directed at apprehended migrants have all made it more difficult for undocumented Latinos to work in the United States on a temporary or seasonal basis over the last two decades. As a result, the undocumented Latino work force is now more permanently settled (Massey et al. 2002) and less likely to voluntarily return to Mexico periodically. Today those who successfully cross the desert are well aware of the magnitude of this accomplishment. Two months after I watched him and Miguel walk into a dark tunnel on the outskirts of Nogales, I caught up with Victor and asked him how he finally entered the United States (see Figure 14):

\begin{abstract}
We walked for five days.... We ran out of food and spent the last two days without anything to eat.... I got very sick from walking so far. My blood pressure dropped very low while I was trying to climb out of a wash.... We ran out of water but were able to find a cattle tank.... The water was very dirty but we drank it anyways.... We ended up throwing away our backpacks and our extra clothes on the fourth day. We put all our water into one backpack and took turns carrying it for a few hours at a time. ... In the end I think we walked more than 60 miles. This was my fifth time trying to cross the desert and I finally made it. ... I keep this backpack as a memento of that last trip.
\end{abstract}

Jason De León Department of Anthropology, University of Michigan, Ann Arbor, MI 48109-1107; jpdeleon@umich.edu

\section{NOTES}

Acknowledgments. Parts of this research were funded by the National Science Foundation (Award \# 0939554), the University of Washington's Royalty Research Fund, and the University of Michigan. I wish to thank Bob Kee, Michael Wells, Jackson Hathorn, Aaron and Madeline Naumann, Ran Boytner and the Institute for Field Research, Consuelo Crow, Robyn Dennis and the Center for Advanced Spatial Technology at the University of Arkansas, and all of the students who participated in the 2010 field school. Special thanks to Steven Ritchey whose data on water bottle temperatures were used in the article and Michael Wells for Figures 3 and 14. In addition, Hannah DeRose-Wilson, Emma Duross, Anna Forringer, Sarah Rybak, and Joia Sanders assisted with the laboratory analysis and photography of artifacts. María Inclán proofread the Spanish abstract. The archaeological field work could not have been carried out without the help and support of the many residents of Arivaca including Fern Robinson, Penny and Steve Shepard, Maggie and Rich Milinovitch, Shaun Quintero, Ronnie, Uncle Jojo, and everyone at the La Gitana Cantina. The ethnographic fieldwork could not have been carried out without the support of Doña Hilda and Don Paco Loureido at the Albergue Juan Bosco migrant shelter in Nogales. I am indebted to my friends Chapo, Chava, Eric, Polo, Netchy, Fernando, and Panchito who introduced me to La Linea and whose stories are interwoven into this narrative. This article has greatly benefited from feedback from several people. First, I am indebted to my wonderful wife, Abigail Bigham, who read many drafts of this article from start to finish. Kirk French, María Elena García, Anthony Graesch, and José Antonio Lucero provided comments on an early draft of this article. University of Michigan graduate students and faculty provided feedback on this article through the Anthro-History Program's writing workshop. I wish to thank the four anonymous reviewers whose insightful comments and critiques significantly improved the quality and coherence of this piece. I also want to thank Tom Boellstorff at American Anthropologist for all of the editorial comments and assistance in translating the reviewer comments into major themes that made the revising process immensely easier. Any mistakes or omissions in the final product are my own. Finally, this work would not have been possible without the help and trust of the many people I have met along the border who have graciously shared their powerful stories with me. Although I cannot name them here, I have tried to repay their generosity by doing my best to accurately document what they experience on a daily basis. Gracias.

1. All names are pseudonyms.

2. Conditions during other seasons such as winter can also be extreme and many people have died from exposure to freezing temperatures. Compared to the summer, the experiences of those crossing during the winter are less known and warrant further research.

3. One liter equals 0.26 gallons.

4. Dusting is a tactical maneuver whereby helicopters descend on migrants in the desert and attempt to blind and disorient them by kicking up dust with their propeller blades.

\section{REFERENCES CITED}

Adler, Rudy, Victoria Criado, and Breet Hunneycutt

2007 Border Film Project: Photos by Migrants \& Minutemen on the U.S.-Mexico Border. New York: Abrams.

Allerton, Catherine

2007 The Secret Life of Sarongs: Manggarai Textiles as Super-

Skins. Journal of Material Culture 12(22):22-46.

Andreas, Peter

2009 Border Games: Policing the U.S.-Mexico Divide. New York: Cornell University Press.

Appadurai, Arjun, ed.

1986 The Social Life of Things: Commodities in Cultural Per-

spective. Cambridge: Cambridge University Press.

Banerjee, Mukulika, and Daniel Miller

2003 The Sari. Oxford: Berg Publishers.

Bourdieu, Pierre

1977 Outline of a Theory of Practice. Cambridge: Cambridge University Press.

Cornelius, Wayne

2001 Death at the Border: Efficacy and Unintended Consequences 
of US Immigration Control Policy. Population and Development Review 27(4):661-685.

Cornelius, Wayne, Scott Borger, Adam Sawyer, David Keyes, Clare Appleby, Kristen Parks, Gabriel Lozada, and Jonathan Hicken 2008 Controlling Unauthorized Immigration from Mexico: The Failure of "Prevention through Deterrence" and the Need for Comprehensive Reform. Technical report. La Jolla: Immigration Policy Center.

Cornelius, Wayne, and I. Salehyan

2007 Does Border Enforcement Deter Unauthorized Immigration? The Case of Mexican Migration to the U.S. of America. Regulation \& Governance 1:139-153.

De León, Jason

In press The Alien Transfer and Exit Program: Migrant Perspectives from Nogales, Sonora, Mexico. International Migration.

Downey, Greg

2007 Producing Pain: Techniques and Technologies in No-HoldsBarred Fighting. Social Studies of Science 37(2):201-226.

Dunn, Timothy

1996 The Militarization of the U.S.-Mexico Border. 1978-1992:

Low-Intensity Conflict Doctrine Comes Home. Austin: University of Texas Press.

Gell, Alfred

1988 Technology and Magic. Anthropology Today 4(2):6-9.

Government Accountability Office

1997 Report to the Committee on the Judiciary, U.S. Senate and the Committee on the Judiciary, House of Representatives, Illegal Immigration: Southwest Border Strategy Results Inconclusive; More Evaluation Needed. http://www. gao.gov/archive/1998/gg98021.pdf, accessed March 1st, 2011.

2006 Report to U.S. Senate; Illegal Immigration: Border Crossing Deaths Have Doubled Since 1995; Border Patrol's Efforts Have Not Been Fully Evaluated. http: / /www.gao.gov/ new.items/d06770.pdf, accessed March 1st, 2011.

Hansen, Karen

2004 The World in Dress: Anthropological Perspectives on Clothing, Fashion, and Culture. Annual Review of Anthropology 33:369-392.

Hoksins, Janet

2006 Agency, Objects and Biography. In Handbook of Material Culture. C. Tilley, W. Keane, S. Küchler, M. Rowlands, and P. Spyer, eds. Pp. 74-85. London: Sage

Institute of Medicine

2004 Dietary Reference Intakes for Water, Potassium, Sodium, Chloride, and Sulfate. Washington, D.C.: National Academies Press.

Jones, Ellen Carol

2001 Empty Shoes. In Footnotes on Shoes. S. Benstock and S. Ferriss, eds. Pp. 197-232. New Brunswick: Rutgers University Press.

Keane, Webb

2006a Signs Are Not the Garb of Meaning: On the Social Analysis of Material Things. In Social Analysis of Material Things. Daniel. Miller, eds. Pp. 182-205. Durham: Duke University Press. 2006b Subjects and Objects. In Handbook of Material Culture. C. Tilley, W. Keane, S. Küchler, M. Rowlands, and P. Spyer, eds. Pp. 197-202. London: Sage.

Latour, Bruno

1992 Where Are the Missing Masses?: The Sociology of a Few Mundane Artifacts. In Shaping Technology/Building Society: Studies in Sociotechnical Change. W. Bijker and J. Law, eds. Pp. 225-258. Cambridge: MIT Press.

Lemonnier, Pierre

1986 The Study of Material Culture Today: Toward an Anthropology of Technical Systems. Journal of Anthropological Archaeology 5:147-186.

MacKenzie, Donald and Judy Wajcman (eds)

1999 The Social Shaping of Technology. Buckingham: Open University Press.

Mauss, Marcel

1973 [1934] Techniques of the Body. Economy and Society 2:7087.

Massey, Douglas, Jorge Durand, and Nolan Malone

2002 Beyond Smoke and Mirrors: Mexican Immigration in an Era of Economic Integration. New York: Russell Sage Foundation.

McCombs, Brady

2011a Border-Crosser Deaths Reach a Low, But Still 182 People

Died. Arizona Daily Star, October 12. http://azstarnet. com/news/local/border/article_97e908b4-5cb9-54a9-

a03e-49341f85dcb6.html, accessed November 30, 2011.

2011b US Deportations Set Record Even as Those from Arizona fall. Arizona Daily Star, October 19. http://azstarnet. $\mathrm{com} /$ news/local/border/us-deportations-set-record-evenas-those-from-arizona-fall/article_bee8c9d0-cdfa-5890-

b8fe-7a033d482c4d.html, accessed November 30, 2011.

Mesenbrink, Johh

2001 Protecting Borders with Thermal Imaging. http: / / www.securitymagazine.com/articles/protecting-

borders-with-thermal-imaging-1, accessed July 25, 2011.

Miller, Daniel

2010 Stuff. Cambridge: Polity Press.

Nevins, Joseph

2002 Operation Gatekeeper: The Rise of the "Illegal Alien" and the Making of the U.S.-Mexico Boundary. New York: Routledge Press.

O'Leary, Anna

2009 The ABCs of Migration Costs: Assembling, Bajadores, and Coyotes. Migration Letters 6(1):27-35.

Parks, K., G. Lozada, M. Mendoza, and L. García Santos 2009 Strategies for Success: Border Crossing in an Era of Heightened Security. In Migration from the Mexican Mixteca: A Transnational Community in Oaxaca and California. W. Cornelius, D. Fitzgerald, J. Hernández-Díaz, and S. Borger, eds. Pp. 31-61. San Diego: Center for Comparative Immigration Studies.

Pfaffenberger, Bryan

1992 Social Anthropology of Technology. Annual Review of Anthropology 21:491-516.

Rubio-Goldmsith, Raquel, Melissa McCormick, Daniel Martinez, and Inez Duarte 
2006 "The Funnel Effect" and Recovered Bodies of Unauthorized Migrants Processed by the Pima County Office of the Medical Examiner 1990-2005. http://immigration.server263. com/indexphp?content $=$ B070201, accessed October 10, 2010.

Sawka, M., S. Cheuvront, and R. Carter III

2005 Human Water Needs. Nutrition Reviews 63(6):30-39.

Singer, Audrey and Douglas Massey

1998 The Social Process of Undocumented Border Crossing Among Mexican Migrants. International Migration Review 32(3):561-592.

Slack, Jeremy and Scott Whiteford

2011 Violence and Migration on the Arizona-Sonora Border. Human Organization 70(1):11-21.

Spener, David

2009 Clandestine Crossings: Migrants and Coyotes on the TexasMexico Border. Ithaca: Corne 11 University Press.

Sundberg, Juanita

2008 'Trash-Talk' and the Production of Quotidian Geopolitical Boundaries in the USA-Mexico Borderlands. Social \& Cultural Geography 9(8):871-890.

Thompson, John

1994 Santo Niño de Atocha. Journal of the Southwest 36(1): $1-18$.
Tilley, Christopher

2006 Objectification. In Handbook of Material Culture. C. Tilley, W. Keane, S. Küchler. M. Rowlands, and P. Spyer, eds. Pp. 60-73. London: Sage.

Wacquant, Loï

1995 Pugs at Work: Bodily Capital and Bodily Labour among Professional Boxers. Body \& Society 1:65-93.

\section{FOR FURTHER READING}

(These selections were made by the American Anthropologist editorial interns as examples of research related in some way to this article. They do not necessarily reflect the views of the author.)

Dorsey, Margaret E

2010 Miguel Diaz-Barriga Beyond Surveillance and Moonscapes: An Alternative Imaginary of the U.S.-Mexico Border Wall. Visual Anthropology Review 26(2):(128-135)

Sandell, David P.

2010 Where Mourning Takes Them: Migrants, Borders, and an Alternative Reality. Ethos 38(2):179-204

Susan, Bibler Coutin

2003 Legalizing Moves: Salvadoran Immigrants' Struggle for U.S. Residency. pp. 228 Ann Arbor: University of Michigan Press. 